\title{
The Effect of Mesh Sizing Toward Deformation Result in Computational Dynamic Simulation for Blast Loading Application
}

\author{
Md Fuad Shah Koslan ${ }^{1}$, Ahmad Mujahid Ahmad Zaidi ${ }^{3}$, Mohd Zaid Othman ${ }^{2}$, Shohaimi Abdullah ${ }^{2} \&$ Suresh Thanakodi $^{3}$ \\ ${ }^{1}$ Royal Malaysian Air Force, Ministry of Defence, Kuala Lumpur, Malaysia \\ ${ }^{2}$ Faculty of Engineering, National Defence University of Malaysia, Kuala Lumpur, Malaysia \\ ${ }^{3}$ International College of Automotive, Pekan, Pahang, Malaysia \\ Correspondence: Md Fuad Shah Koslan, Royal Malaysian Air Force, Ministry of Defence, Kuala Lumpur, \\ Malaysia. Tel: 60-12-265-1302. E-mail: fuadpostgrad@gmail.com
}

Received: May 9, 2013

doi:10.5539/mas.v7n7p23
Accepted: June 7, $2013 \quad$ Online Published: June 18, 2013

URL: http://dx.doi.org/10.5539/mas.v7n7p23

\begin{abstract}
The finite element approach was used in the simulation analysis to solve many engineering problems. One of the accuracy factors of this method is dependent on the choice of appropriate element size or mesh discretization. Good mesh discretization can reduce the percentage of error; avoid the computation time approaches to non-practical limits and furthermore, produces the optimal results. The purpose of this study is to identify the best size of mesh elements to be used in the problem analysis using the AUTODYN numerical simulation. The fully clamped circular plate subjected to blast load as per experimental setup was modified and simplified in the two-dimensional (2D) simulation model; it will be seen as a clamped beam at both edges. Plate model were discretized to form nodal and element. The deformation or deflection result found to converge at certain value by increasing the total number of element discretization. Assumed that the deformation results were accurate at the converged state; it will be taken as reference to choose the finest size of mesh element. In this study, several mesh sizes been considered, and the appropriate optimum mesh discretization obtained at range of $0.5 \mathrm{~mm}$ to 1 $\mathrm{mm}$.
\end{abstract}

Keyword: finite element, AUTODYN, mesh sensitivity, 2D

\section{Introduction}

Analysis the behaviour of the structure when subjected to blast loading by using the numerical simulation has been developed with several techniques. Results obtained in the simulation then compared with experimental for validation purpose, thus contributes to reduction of the total experiments need to be carried out. With the rapid development of computing technology in the recent years, researchers have focused on the numerical simulation which is more convenient and economical.

AUTODYN is one hyrocode program used to resolve problems involving the interaction of structural, fluid and gas simultaneously. This application normally used in the blast and ballistic analysis. Integration of pre-processor, post processors and analysis execution code found in this software make it easier to use and more user-friendly. AUTODYN also allows different solver (or processor) as Lagrange, Euler to function simultaneously in a one model analysis.

Daniel (2009) used AUTODYN 3D to analyse the effect of blast toward stand-off distance in blast test, and he studied the propagation of wave explosion in the confinement area. Amstrong and Walley (2008) used the Johnson Cook constituting equation in AUTODYN to estimate temperature rises within the crystals in the analysis dynamic recrystallization and spallation or fragmentation.

There are three types of Eulerian solver in AUTODYN: Euler, Euler Godunov and Euler Flux Corrected Transport (FCT Euler). Euler solver used in AUTODYN 2D is based on first-order approach. It allows multi-material to be modelled. However, for second order scheme is only available in AUTODYN 3D. Eulerian element size 5, 2.5, 1.25, 1, 0.625 and $0.5 \mathrm{~mm}$ used in order to analyse the effect of mesh sensitivity toward the result. The appropriate meshing size obtained then used for future analysis. 


\section{Simulation Model}

The modified simulation model carried out referring to experiment has performed by Neuberger, Peles, and Rittel (2009). The experimental setup was shown in Figure 1. The circular target plate with diameter $1000 \mathrm{~mm}$ clamped with two thick armor steel ring, tighten together with bolt and clamped, while $8.75 \mathrm{~kg}$ of TNT explosive charge with $0.2 \mathrm{~m}$ stand-off in distance. In 2D simulation the target seen as a beam and in this experiment TNT were modified using only $1.1 \mathrm{~kg}$ in order to avoid element distortion during analysis. The cross sectional diagram and involve parameter shown in Figure 2.

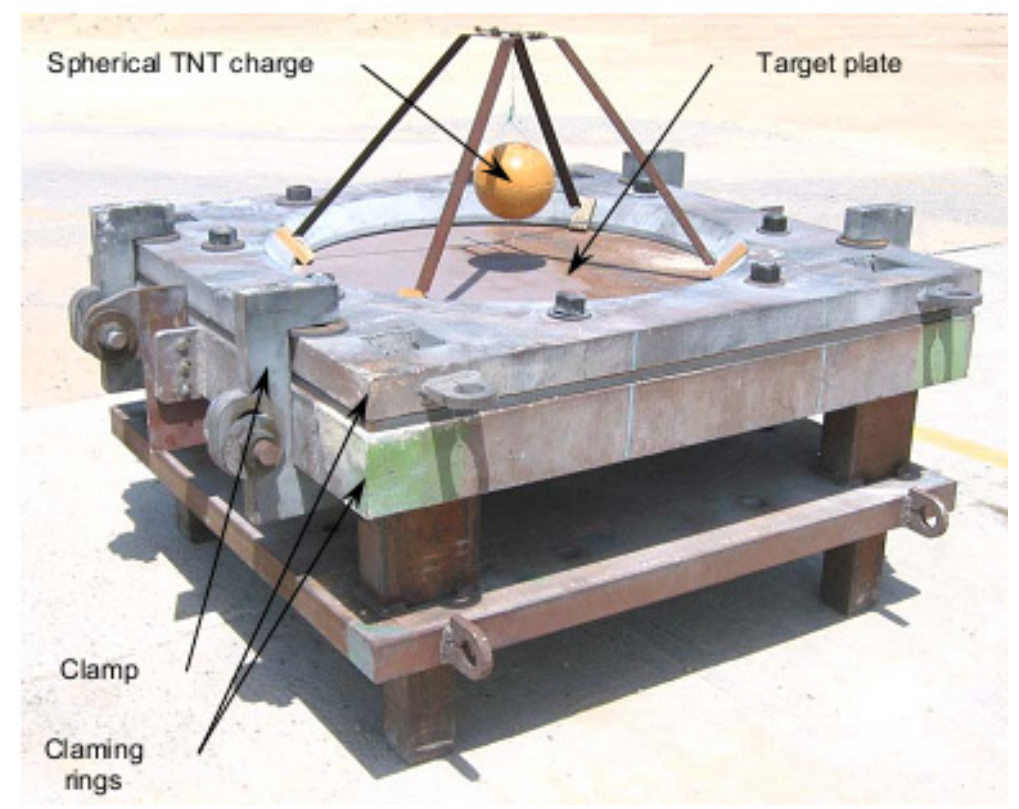

Figure 1. Experimental setup (Neuberger, Peles, \& Rittel, 2009)

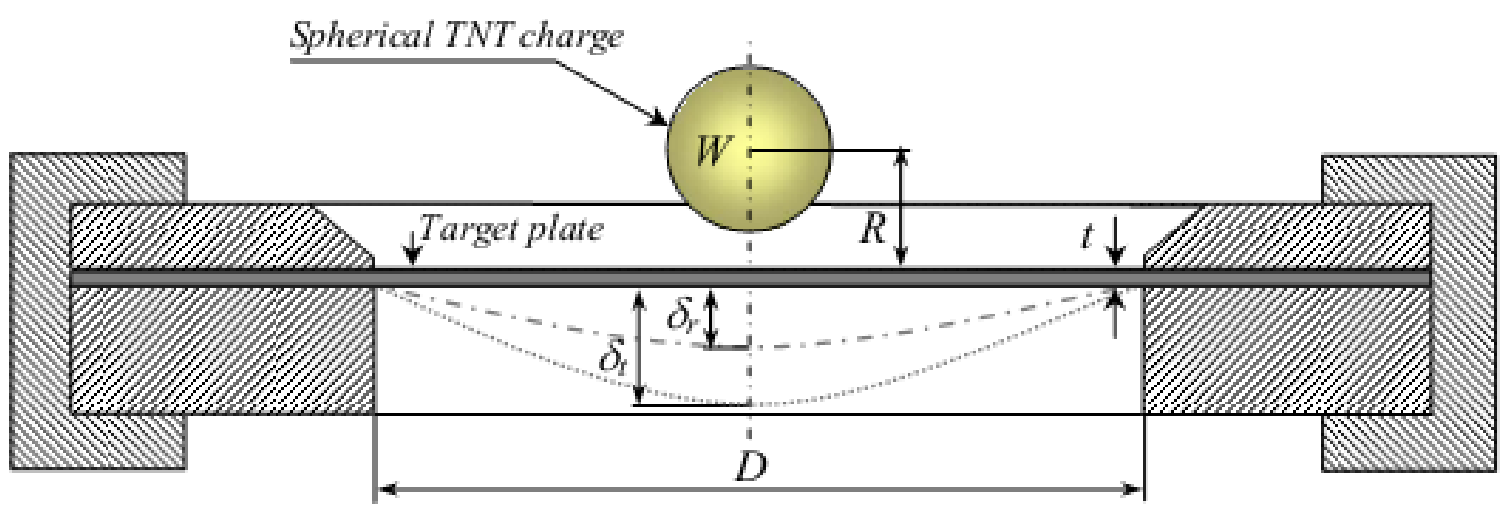

Figure 2. 2D cross sectional diagram (Neuberger, Peles, \& Rittel, 2009)

The simulation conducted using high speed computer processor Intel® Core ${ }^{\mathrm{TM}}$ i7-2600K CPU@ $3.40 \mathrm{GHz}$ (8CPUs), 3.7 GHz. A 2D axis-symmetric model was developed using Langrage and Multi-Material Euler solver. The model was created in the domain size $500 \mathrm{~mm}$ x $450 \mathrm{~mm}$ defined as air symmetry in $\mathrm{x}$ - axis. Material properties of Steel 1006 with Johnson Cook material model found available in AUTODYN libraries were used to represent the plate. Ideal gas equation of state was chosen to describe air and Jones Wilkins Lee (JWL) equation of state describes the TNT explosive charge. Eulerian elements were used to represent air and TNT and Langrage element were used to represent the plate. Four gauge were pasted at the plate as shown in Figure 3. Gauge 1, 2, 3 and 4 were located at $250 \mathrm{~mm}, 125 \mathrm{~mm}, 100 \mathrm{~mm}$ and $50 \mathrm{~mm}$ respectively from symmetrical axis and plate were fully clamped at the end of the edge. 


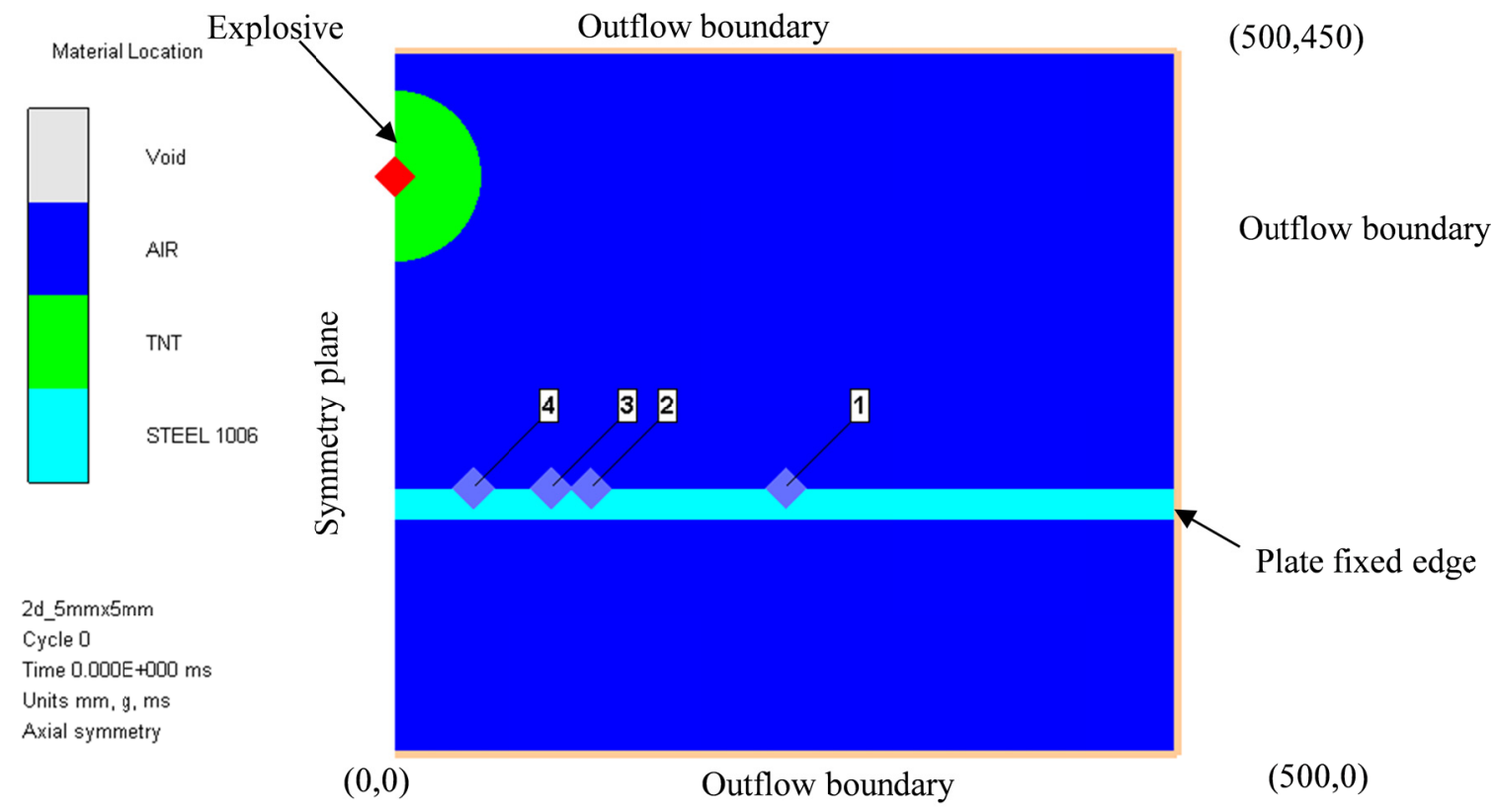

Figure 3. AUTODYN 2D multi-material axis-symmetry simulation model

\subsection{Material Properties}

The equation of state and strength models was used to describe the material in the numerical simulation. The Johnson and Cook material was used in by Wisniewski and Tomaszewski (2009) in a computer simulation of AP projectile penetration into RHA and on analysis of the response of V-shape plates to localise blast load (Chung-Kim-Yuen et al., 2012). Johnson and Cook material model expressed the flow stress as a function of plastic strain rate and temperature as follow:

$$
\sigma_{Y}=\left[A+B\left(\bar{\varepsilon}_{p l}\right)^{n}\right]\left[1+C \ln \left(\frac{\dot{\varepsilon}_{p l}}{\dot{\varepsilon}_{0}}\right)\right]\left[1-\left(\frac{T-T_{\text {room }}}{T_{\text {melt }}-T_{\text {room }}}\right)^{m}\right]
$$

where $\sigma_{Y}$ known as the yield stress at non zero strain, $\bar{\varepsilon}_{p l}$ as the affective plastic strain, $\dot{\varepsilon}_{p l}$ as the normalized, $T$ as the material temperature $(\mathrm{K})$ and $T_{\text {melt }}$ as the melting temperature of the material. The constant $A, B, n, C$, $m$ and $\dot{\varepsilon}_{0}$ normally user-defined constant and obtained from an empirical of flow stress data. In the AUTODYN library all the parameter for steel 1006 was given as in Table 1 .

Table 1. Material properties for Steel 1006

\begin{tabular}{ccccccc}
\hline$A(M P a)$ & $B(M P a)$ & $n$ & $C\left(s^{-1}\right)$ & $m$ & $T_{\text {melt }}(K)$ & $\dot{\varepsilon}_{0}\left(s^{-1}\right)$ \\
\hline 270 & 275 & 0.36 & 0.22 & 1.00 & 1811 & 1 \\
\hline
\end{tabular}

\subsection{Properties of Air}

In AUTODYN, an ideal gas equation of state used to describe air as per Equation (2) below:

$$
P=P_{\text {shift }}+\rho e(\gamma-1)
$$

Where $\mathrm{P}$ is the pressure, $P_{\text {shift }}$ known as small pressure defined provides initial pressure and in this case was set as zero, $\gamma$ known as the adiabatic constant estimated to be at 1.4 as an ideal gas, $\rho$ the density and $e=c_{v} T$ the specific internal energy. Since the air model already available in AUTODYN library and the value set as per Table 2. 
Table 2. Properties of air

\begin{tabular}{|c|c|c|c|c|}
\hline $\begin{array}{c}\rho \\
\left(\mathrm{kg} / \mathrm{m}^{3}\right)\end{array}$ & $\begin{array}{c}T \\
(K)\end{array}$ & $\begin{array}{c}C_{p} \\
(k J / k g K)\end{array}$ & $\begin{array}{c}C_{v} \\
(k J / k g K)\end{array}$ & $\begin{array}{c}E \\
(\mathrm{~kJ} / \mathrm{kg})\end{array}$ \\
\hline 1.225 & 288.2 & 1.005 & 0.718 & $2.068 \times 10^{5}$ \\
\hline
\end{tabular}

\subsection{Properties of Explosive}

The Jones-Wilkins Lee (JWL) equation of state were used in AUTODYN to describe the explosive pressure $P$, as per Equation (3):

$$
P=A\left[1-\frac{\omega}{R_{1} V}\right] e^{-R_{1} V}+B\left[1-\frac{\omega}{R_{2} V}\right] e^{-R_{2} V}+\frac{\omega E}{V}
$$

where $A, B, R_{1}, R_{2}, \omega$ empirically derived constant which provides different constant value for different explosives. $V$ was known as the relative volume or the expansion of the explosive product, and $E$ as the detonation energy per unit volume. In this simulation PE4 were chosen as an explosive charge in order to suit with the experimental setup. Since the TNT is an available explosive model in AUTODYN, the PE4 and TNT equivalency be defined. In the experimental and simulation result done by (Hungtington-Threshe \& Cullis, 2001) it was obtained for PE4 and TNT pressure equivalency at 1.37, TNT impulse equivalency at 1.1 and weight equivalency at 1.3. Based on TNT density of $1.63 \times 10^{3} \mathrm{~kg} / \mathrm{m}^{3}$ as asserted in (Daniel Ambrosini et al., 2009): simulation model for explosive was created based on the radius of TNT; $1.1 \mathrm{~kg}$ TNT equivalent with 1.43 PE4 in a hemispherical shape has radius of $55 \mathrm{~mm}$.

\section{Results and Discussion}

The simulation results in Figure 4 shows the maximum deflection occurred at the position farthest from the tip of the clamped edge. This means that if a circle or a square plate maximum deflection occurs at the midpoint. The number of elements used showed a significant effect on the final deformation of the plates. Assumed in this case, data for $5 \mathrm{~mm}$ element used as a datum, it can be seen the percentage difference at the maximum deflection at gauge 4 increasing with the increase of number of elements up to 19 percent. The percentage difference can be seen in Table 3. As total of 9000 elements with $5 \mathrm{~mm}$ element sizes were produced computational time to analyse in 12 minutes while on the size of $0.5 \mathrm{~mm}$ or total about 0.9 million elements taken 38.5 hours with 19 percent difference.

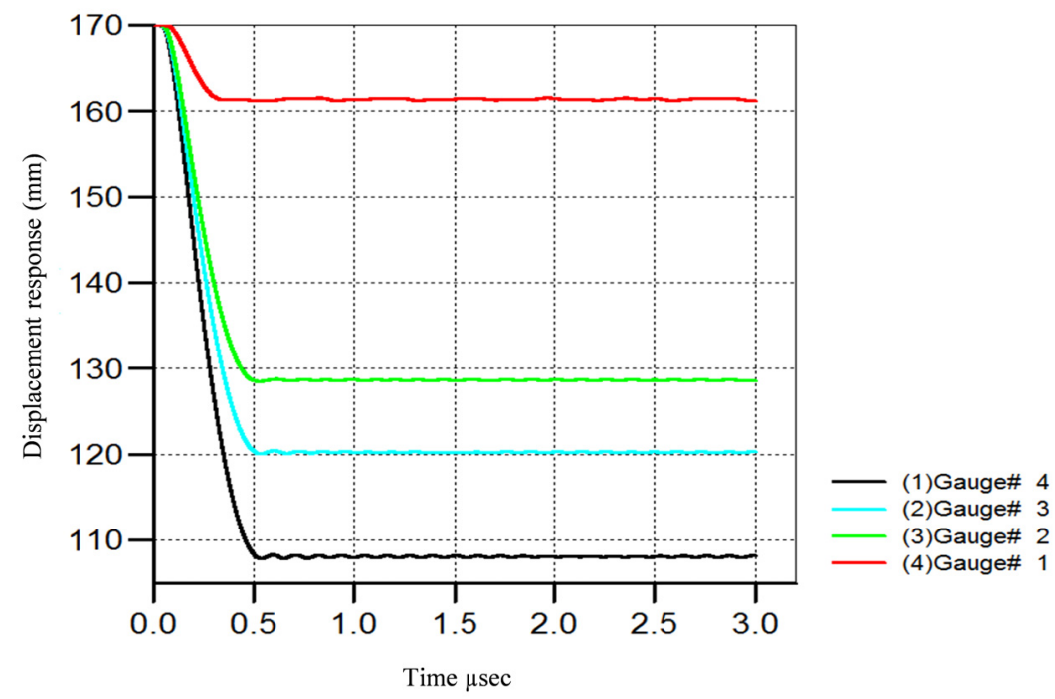

Figure 4. Deflection reading

In this simulation model the relationship was seen as there is a trade-off between the mesh size and the hardware capabilities. It's found that as the number of element increase, the computational time does increase accordingly per in Figure 6. 
Table 3. Result analysis for all samples

\begin{tabular}{|c|c|c|c|c|c|c|c|c|}
\hline \multirow{2}{*}{$\begin{array}{l}\text { No. of } \\
\text { Sample }\end{array}$} & \multirow{2}{*}{$\begin{array}{l}\text { Size of } \\
\text { Element } \\
(\mathrm{mm})\end{array}$} & \multirow{2}{*}{$\begin{array}{c}\text { No. of } \\
\text { Element } \\
\text { (thousand) }\end{array}$} & \multicolumn{4}{|c|}{ Maximum Deformation (mm) } & \multirow{2}{*}{$\begin{array}{c}\% \text { Change } \\
\text { Max Deform } \\
\text { at Gauge } 4\end{array}$} & \multirow{2}{*}{$\begin{array}{l}\text { Time } \\
\text { Taken } \\
(\mathrm{Hrs})\end{array}$} \\
\hline & & & Gauge 1 & Gauge 2 & Gauge 3 & Gauge 4 & & \\
\hline 1 & 5 & 9 & 8.76 & 41.48 & 49.92 & 62.15 & 0.00 & 0.2 \\
\hline 2 & 0.625 & 576 & 8.27 & 45.18 & 56.16 & 73.55 & 18.34 & 17.60 \\
\hline 3 & 0.5 & 900 & 8.28 & 45.08 & 56.16 & 73.92 & 18.94 & 38.50 \\
\hline
\end{tabular}

The maximum deflection will converge when crossing the total 500 thousand of elements is shown in Figure 5. It was worth to get such results in a long time to avoid 19 percent error.

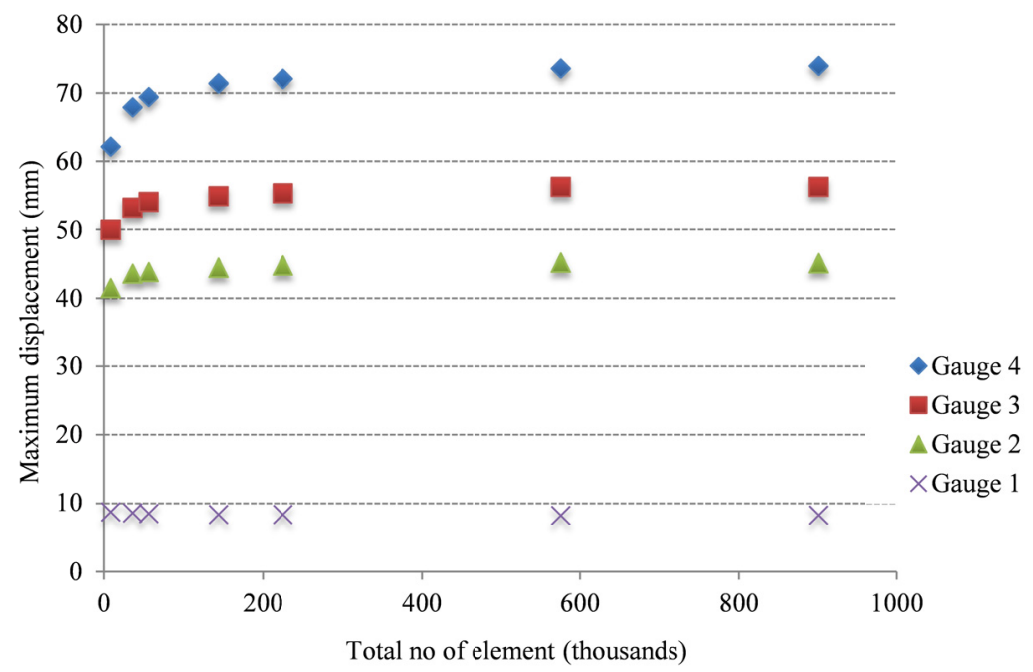

Figure 5. Maximum deflection for each gauge toward total no of element

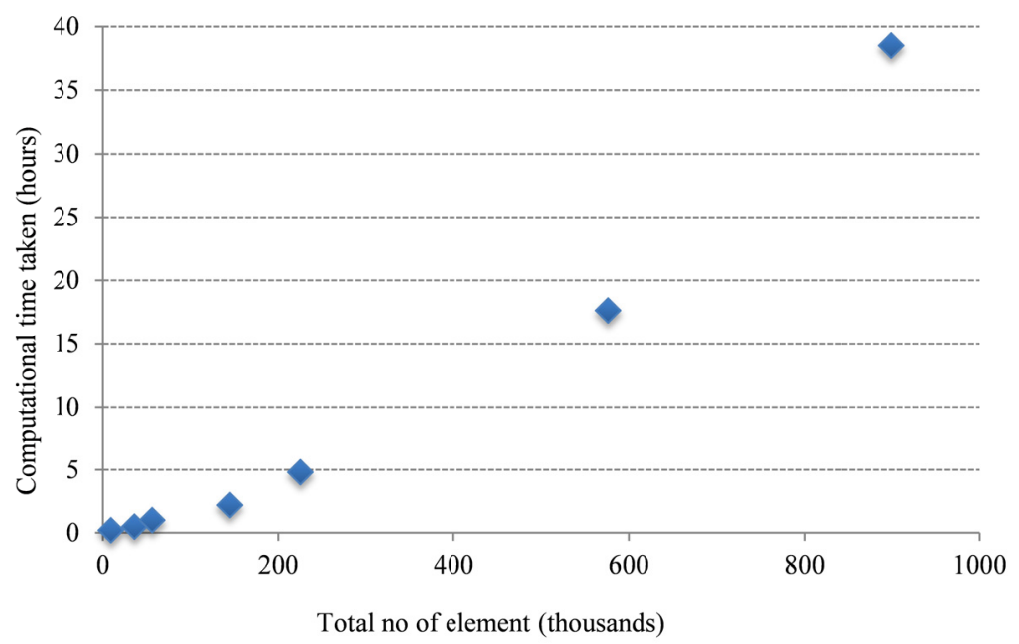

Figure 6. Computational time taken in hours for analysis 


\section{Conclusions}

Model simplification is a very important in simulation analysis. The ability to simplify the model facilitates an analysis by shorten the time taken and produce good results. The selection of mesh size found to be one of the factors to determine the accuracy of the results produced. Common error occurs in simulation analysis is due to the insufficient of refinement finite element grid.

Noted that the number of elements or grid that too much also causes the computation time approaches to non-practical limit and also sometime the results found not promising. In this case, the selection of the mesh found to be in the range from $0.5 \mathrm{~mm}$ to $1 \mathrm{~mm}$ considered as the best element size for the analysis using AUTODYN software.

\section{Acknowledgements}

Financial assistance from the Royal Malaysian Air Force (RMAF) towards this research is hereby acknowledged. Opinions and views either directly or indirectly from various parties, including the staff and lecturers from engineering research center of National Defense University (UPNM) greatly appreciated.

\section{References}

Ambrosini, D., Luccioni, B., Nurick, G., Langdon, G., \& Jacob, N. (2009). The effect of confinement and stand-off distance in blast tests. Mecanica Computacional, XXVII, 343-362.

Armstrong, R. W., \& Walley, S. M. (2008). High strain rate properties of metals and alloys. International Materials Reviews, 53(3), 105-128. http://dx.doi.org/10.1179/174328008X277795

Chung-Kim-Yuen, S., Langdon, G. S., Nurick, G. N., \& Pickering, E. G. (2012). Response of V-shape plates to localised blast load: experiment and numerical simulation. International Journal of Impact Engineering, 46, 97-109. http://dx.doi.org/10.1016/j.ijimpeng.2012.02.007

Hungtington-Thresher, W. K. E., \& Cullis, I. G. (2001). TNT blast scaling for small charges. $19^{\text {th }}$ International Symposium of Ballistics, Interlaken, Switzerland.

Neuberger, A., Peles, S., \& Rittel, D. (2009). Springback of circular clamped armor steel plates subjected to spherical air-blast loading. International Journal of Impact Engineering, 36, 53-60. http://dx.doi.org/10.1016/j.ijimpeng.2008.04.008

Wisniewski, A., \& Tomaszewski, L. (2009). Computer Simulation of AP Projectile Penetration into RHA. Project report of Technology of production of superhard nanostructural Fe-based alloys and their application in passive and passive-reactive armors. Military Institute of Armament Technology, Poland.

\section{Copyrights}

Copyright for this article is retained by the author(s), with first publication rights granted to the journal.

This is an open-access article distributed under the terms and conditions of the Creative Commons Attribution license (http://creativecommons.org/licenses/by/3.0/). 